\title{
Evidence of Faculty Salary Differences Across Business Disciplines and Employment Contracting Systems
}

\author{
Sandra Schrouder \\ School of Professional and Career Education, Barry University \\ 11300 NE 2nd Avenue, Miami Shores, FL 33161-6695, US
}

Marcus T. Allen (Corresponding author)

Department of Economics and Finance, Lutgert College of Business

Florida Gulf Coast University

10501 FGCU Boulevard South, Fort Myers, Florida 33965, US

E-mail: timallen@fgcu.edu

Rupert G. Rhodd

College of Business, Florida Atlantic University

2912 College Avenue, Fort Lauderdale, Florida 33314, US

\author{
Travis L. Jones \\ Department of Economics and Finance, Lutgert College of Business \\ Florida Gulf Coast University \\ 10501 FGCU Boulevard South, Fort Myers, Florida 33965, US
}

Received: March 13, 2019

Accepted: March 25, 2019 Published: March 31, 2019

doi:10.5296/ijafr.v9i1.14493

URL: https://doi.org/10.5296/ijafr.v9i1.14493 


\section{MlMacrothink}

\section{Abstract}

Using sample data from two accredited business schools in the Florida State University System, one non-tenure granting and one tenure granting, and regression analysis, this paper explores variation in faculty salary levels across business disciplines. The results indicate (1) that accounting and finance professors earn more than management professors, thus receiving a salary premium in the market, (2) that marketing and information systems/operations management faculty earn no significantly different salaries than management professors, and (3) that economics professors earn less than management professors and thus receive a discount in the market. The results also indicate that rank, administrative duties, years in the profession, and research productivity are significant determinants of the salaries of business professors, but that salaries in this sample are unrelated to gender and race. The findings also provide evidence of salary inversion, with assistant professors receiving larger salaries than associate professors. The unique results of this study are that salary discounts and premiums by discipline are similar at both non-tenure granting and tenure granting universities.

Keywords: Employment contracting systems, Business schools, Salary levels, Business disciplines

\section{Introduction}

Research on the management of human resources notes that attracting, developing, and retaining qualified employees are essential processes for the success of any organization (Ehrenberg, Hirschel \& Rees (1990); Kreuter 2012; Sinha \& Sinha (2012)). For academic institutions, the quality of its programs is determined in large part by the effectiveness of its faculty on three primary dimensions: research, teaching, and service. Lavania, Sharma and Gupta (2011) note that "it is the faculty that sets the tone of an educational institution" (p. 1).

Economic theory teaches that the salary paid to any factor of production, in this case university faculty, is determined in the market place by the forces of demand and supply. Whereas demand factors are institution-determined, supply factors are faculty-determined. This study applies this line of thought to business school faculty. Using data from two accredited business schools in the Florida State University System, this paper explores relationships between the salary levels of faculty in various business disciplines to evaluate whether or not some disciplines command premiums or suffer discounts relative to other disciplines.

Because these two schools use different employment contracting systems (one tenure granting and one non-tenure granting with full-time faculty employed on rolling, three-year contracts), this sample provides a unique laboratory for examining potential faculty salary differences across business school disciplines. Analyzing data from these two schools may give insight into the significance of tenure vs. non-turning faculty employment contracting on relative salary levels across business disciplines. More specifically, this study may shed light on the issue of whether or not the implied or perceived ease of terminating faculty at a school with non-traditional employment contracting (relative to a tenure granting school) results in different patterns of salary discounts and premiums across business disciplines. 


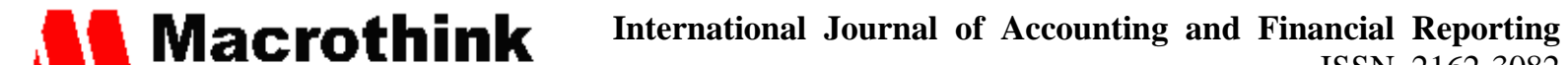 Institute"'

This research has implications for the management of education through the ways education is funded in public universities. For example, it has implications for managing faculty resources through performance funding. In Florida, support from the governor and legislature is based in on metrics that includes (but not limited to) graduation rates, the number of students taught, and the ability to attract "world class faculty." Also, there is the $21^{\text {st }}$ Century World Class Scholars program that provides matching funds to state universities to attract nationally-recognized faculty. As members of the Florida State University System, funding to universities as indicated above could amplify the premiums faculty in different majors receive. Furthermore, with the quality of research being easily determined through the ranking of journals by the Australian Business Deans' list (ABDC Journal Quality) and the Association of Business Schools' Academic Journal Guide (ABS list), this argument seems intuitive and compelling as paying for research performance provides an incentive to spend time increasing one research productivity and salary, especially in the State of Florida where faculty salary increases occur very infrequently. One could also hypothesize that the unit with the best performance mechanism for research will attract faculty with higher research output and this could affect the salaries premiums. It is therefore up to the deans and department chairs to set the standards for research high enough to attract the best scholars as they seek to manage research productivity and salaries in their departments.

With data from both schools combined, the results indicate no significant difference between salaries of management, marketing, and information systems/operations management faculty, but significant salary premiums for accounting and finance faculty and significant salary discounts for economics faculty. Separate analysis of data from each school suggests similar, but not identical results. These findings indicate that variations in salaries across business disciplines tend to persist at schools with traditional and non-traditional employment contracting systems. The analysis controls for academic rank, administrative assignments, years in the profession, gender, race, and research productivity.

The results of this study should prove valuable to administrators and faculty members who seek to better understand salary levels, especially when contemplating salary adjustments, new job opportunities, and employment contracting systems. The next section discusses selected previous research studies on the topic of faculty salaries. Section III describes the data used in the empirical analysis in this paper. Section IV discusses the analysis method, and Section $\mathrm{V}$ presents the findings of the regression estimation. The final section summarizes the paper.

\section{Prior Related Studies}

To the extent that the curricula for accounting and finance $\mathrm{PhD}$ programs are more challenging than curricula in $\mathrm{PhD}$ programs for other business school disciplines, fewer people may choose to pursue $\mathrm{PhDs}$ in these disciplines Furthermore, graduates holding undergraduate and masters' degrees in accounting and finance (especially those with the Certified Public Accounting (CPA) and Chartered Financial Analyst (CFA) designations) may have higher opportunity costs than graduates with undergraduate and masters' degrees in other disciplines when choosing to pursue a $\mathrm{PhD}$ over a professional career in the business 
world. Together, these two issues suggest that the supply of terminally-degreed faculty in accounting and finance may be less than the supply of faculty in other business disciplines (Detailed information about median annual wages for various occupations can be found at the U.S. Department of Labor, Bureau of Labor Statistics website: http://www.bls.gov/ooh/business-and-financial/home.htm, accessed 8/27/16.)

An early study Mohanty, Dodder \& Karman (1986) make analogous arguments in their study of faculty salaries, noting that salary differences are attributable to demand and supply factors in different discipline and with certain variables associated with faculty rank, including number of publications, age, and length of time in rank. Mohanty, Dodder \& Karman (1986) note that the numbers of people receiving doctorates in certain disciplines (business and management, engineering, and computer and information sciences) may lag behind demand increases and this lag affects faculty salaries in a positive manner. Because this study was completed in 1986, it is possible that demand and supply conditions today may be different from what they were at that time. Also today, market factors have taken on added importance in determining faculty salaries in business schools due to relatively larger enrollment growth caused by increased demand for business students seeking to major in finance and/or accounting. This is the result of high salaries paid to finance and accounting graduates in industry. Higher salaries for holders of undergraduate and masters' degrees in these disciplines increases the pressure for administrators to provide more capacity in accounting and finance courses and may lead to salary premiums for accounting and finance faculty compared to faculty in other business school disciplines.

Research by Fairweather (2005) looks at the issue of whether or not commitment to teaching and learning and to restoring the balance between teaching and research is reflected in faculty compensation; and whether or not the monetary value of teaching and increases in salaries over a 5-year period vary by type of institution. Fairweather (2005) notes the faculty salaries are determined either by market competition (supply and demand factors) or institutional forces. In terms of supply and demand factors, Fairweather (2005) notes that "institutions value prospective and current faculty who show research promise or who produce high levels of scholarship" (p. 403). Fairweather (2005) also highlights the market segmentation school of thought that singled out teaching-oriented institutions and their willingness to pay "their most productive and highest quality teachers more than they pay faculty members who publish and obtain external funding" (Fairweather (2005); p.403), versus research universities that pay for research productivity. Looking at institutional norms, Fairweather (2005) notes the earlier research by Hearn (1999) that saw faculty salaries being determined by institutional policy, which at times is used to decrease the effects of markets by taking into account seniority and internal measures of merit. The implication from Hearn (1999) that is relevant to this research is that Deans and department leaders in business schools do not have to focus on research to determine faulty salaries, but can adopt policies that are related more to teaching and service.

Finch, Allen \& Weeks (2010) use a similar argument when noting that the retirement of baby-boomers is reducing the supply of available replacement faculty and that the resulting changes in the market is increasing starting salary levels in business disciplines in general. Applying this reasoning along with the limited supply condition imposed by subject matter 
difficulty and high salary levels at the undergraduate and masters' level, faculty in the accounting and finance disciplines may earn significant salary premiums compared to other disciplines. In the case of economics faculty, Bergeth (2007) finds that the salaries of economics faculty depend on whether or not the department is in the business school (salaries are higher for economics faculty in economics programs housed in business schools) and that, on average, economics faculty tend to be paid less than other business school faculty.

A study by Boudreau et al. (1997) considers the determinants of salaries in business schools by examining the relationships between gender and academic rank on salary levels. They find that rank is a significant determinant of salaries but that gender is not a significant determinant of salary when the effects of rank are controlled for in their analysis

Ashraf \& Shabbir (2006) consider the importance of racial differences in salary determination at universities. They find that the salaries of black assistant professors exceed those of white assistant professors, but that the salaries of white associate professors exceed those of black associate professors. This finding leads them to conclude that increased emphasis on racial diversification in academia has led to higher entry-level salaries for blacks compared to their white counterparts.

Using economic theory and data from the American Economic Association, Coupé, Smeets and Warzynski (2012) sought to relate the wage structure in US universities economics departments to research performance. Noting that a) firms often design their wage policies to serve different purposes; b) that through its wage policy, a firm's rewards employees for their investments in human capital; c) firms provide incentives for individuals to work in the best interest of the firm; and d) that wages can be used to extract information from workers about their abilities thereby helping firms to assign individuals to their most productive use, Coupé, Smeets and Warzynski (2012) hypothesized and did prove that that economics departments can use compensation incentives to increase research productivity. The research by Coupé, Smeets and Warzynski (2012) is important to this paper because it also focused on the tenure decision, promotion, and outside option. Noting that tenure and promotion decisions provide incentives for individuals to work hard to publish their research in good journals, Coupé, Smeets and Warzynski (2012) also looked at these decisions' influence on incentives economics professors' individual behavior.

There are many important findings from the research by Coupé, Smeets and Warzynski (2012): pay differentiation between job levels depends on past achievement; higher wage gaps can be partly explained by higher past publication gaps; length of service can explain wage differences; publications performance tends to reach its peak at about the $11^{\text {th }}$ year; assistant and associate professors are more productive than full professors, and assistant professors are more productive than associate professor. This means that the compensation incentivizes assistant professor more than associate and full professors. However, what is missing in the research by Coupé, Smeets and Warzynski (2012) are the premiums paid to assistant professors over associate and full professors; and the comparison of economics professors with other professors in Business school. This research fills both of these gaps. 


\section{MInstitute ${ }^{\text {Mech }}$}

International Journal of Accounting and Financial Reporting

ISSN 2162-3082

2019, Vol. 9, No. 1

The paper by Martinello (2009) uses faculty salaries from 15 Canadian Universities between 1970 and 2005 to look whether or not different forms of collective representation (unions and special plans, with and without binding arbitration) determine differences in salary levels, and the effect of compensation on research productivity. Martinello (2009) study found that union representation and non-union representation had no effect on salaries; that salaries for the sample were inversely related to the proportion of female faculty but only for the 1970s; and that salaries were higher for universities with higher research productivity. From a management perspective, Martinello (2009) notes that the paper and its results "may be relevant for the increasing numbers of employees in other labor markets who desire some form of representation in the workplace but do not want, or are denied access to, traditional unionism" (p. 128).

Three more recent publications on faculty salary levels are also worthy of note. Kreuter (2012) identifies several factors that impact the salary a faculty receives. These factors include the faculty's discipline; the nature of the institution at which the faculty is employed; and whether or not the job is tenure-track. Research by Yang \& Webber (2015) on the effects of PhD activity 10 years after graduation shows that although the postdoctoral experience has no statistically significant impact on faculty salaries a decade after degree completion, postdoctoral studies/positions help to secure tenure-track appointments. Furthermore, there is a positive correlation between the number of postdoctoral positions and scholarly productivity. Allen, Jones, \& Rhodd (2015) consider the issue of salary compression and find salary compression to be associated more with the number of years at the institution at tenure granting schools, but more associated with years in the profession at non-tenure granting schools.

Using a survey that includes over 100 universities in the United Kingdom, a recent paper by McCormack, Propper and Smith (2014) looked at management practices that are supposed to predict department performance. They found that in older departments research output is higher than in newer departments where there is more emphasis on teaching. From Table 1 in the next section, the average salary for the newer non-tenure granting business school being lower $(\$ 109,413)$ than the average salary of faculty at the tenure granting older business school $(\$ 115,554)$, leads to the conclusion that in managing the college and departments in the college, the dean and chairs in the tenure granting business school are more focused on attracting scholars with better research records and are willing to pay higher salaries. The newer non-tenure granting institution is more focused on attracting students and tends to higher faculty with strong teaching records. McCormack, Propper and Smith (2014) also confirmed that management matters in all universities (older and newer universities), especially with respect to provision of incentives for staff recruitment, retention and promotion.

\section{Data Description}

The empirical analysis in this study is based on faculty-level data from two business schools in public universities accredited by the Southern Association of Colleges and Schools (SACS) that are part of the Florida State University System. The first university is the only non-tenure 
granting university in the Florida State University System, while the second university offers traditional tenure-track faculty positions.

The non-tenure granting university was founded in 1991, but did not offer its first classes until 1997. It has five colleges, including a College of Business, and serves approximately 14,000 students at a single campus. The College of Business has seven undergraduate degree programs: accounting, economics, finance, information science, operations management, management, and marketing. The College of Business has three graduate degree programs: accounting and taxation (M.S), business administration (MBA), and executive business administration (Executive MBA).

The second university, the traditional, tenure-granting university, was opened in 1964, and currently serves just more than 30,000 students across seven campuses. This university has ten colleges including a College of Business which serves just over 8,500 students. The College of Business has six departments (Accounting, Economics, Finance, Information Technology and Operations Management, Management, and Marketing), and a number of interdisciplinary and professional development programs. The College of Business has nine undergraduate majors (accounting, economics, finance, health administration, hospitality management, international business \& trade, management, management information systems, and marketing); fourteen masters degrees programs; and five doctoral concentrations.

Other observable similarities and differences between the Colleges of Business at these two universities are as follows. The College of Business in both schools offers a large number of undergraduate minors including economics, entrepreneurship, business administration or management, computer information system or management information systems, finance, health services, operations management, and real estate. Whereas the College of Business in the non-tenure granting university has eight research centers and institutes, the College of Business in the tenure-granting university has only four research centers and institutes. Also, there is no $\mathrm{PhD}$ program in the non-tenure granting College of Business while there is a $\mathrm{PhD}$ program in the tenure-granting College of Business.

In the 2013-14 academic year, the non-tenure granting university employed close to 70 faculty members (eminent scholars, professors, associate professors, assistant professors, instructors, and adjunct professors). In the same year, the tenure-granting university employed more than twice that amount, 189. A closer look at these numbers shows 50 full-time time faculty members at the non-tenure granting university and just over 90 full-time faculty members at the tenure-granting university.

The two universities hire faculty with different employment contracting procedures and thus provide a unique opportunity to study salary determinants and differences. The non-tenure granting university employs full-time faculty members based on a three-year, rolling contracts with administrators completing faculty evaluations each year based on teaching, service, and research productivity. Faculty who receives acceptable annual evaluations receives a new, three-year rolling contract. Promotions from assistant professor to associate professor and from associate to professor are determined by a minimum "time in rank" of five years and satisfactory overall performance while in rank with emphasis on research 
productivity. For the tenure-granting university, administrators also complete faculty evaluations annually, and, if earned, grant tenure and promotion from assistant professor to associate professor within six years of the initial hire date (or be terminated). However, there is no defined minimum or maximum time in rank for promotion from associate professor to professor. Such promotions depend primarily on overall performance with an emphasis on research productivity.

For the tenure-granting university, the standard teaching load is five courses per year for assistant professors, associate professors, and professors. Department chairs and associate deans teach 2 courses per year and eminent scholars teach between 2 to 4 courses per year. Instructors teach eight courses per year. The standard teaching load at the non-tenure granting university is six courses per year for assistant professors, associate professors, and professors; four courses per year for eminent scholars, and faculty members with administrative assignments; and eight courses per year for instructors.

Faculty promotion to the next higher rank at both universities is based on a peer and administrative performance evaluation process, with significant involvement from university-level administration. In both institutions research productivity is more heavily weighted than teaching or service productivity in promotion considerations. Successful completion of the promotion evaluation process results in percentage-based salary adjustments as defined in each university's Collective Bargaining Agreement.

Table 1 provides summary statistics and variable definitions from the full sample used in this study that combines information from both business schools. The average 2013-2014 salary for instructional faculty members is $\$ 113,392$, ranging from a minimum of $\$ 38,075$ to a maximum of $\$ 198,500$. The combined data show that $8 \%$ of the faculty hold the rank of instructor, $21 \%$ hold the rank of assistant professor, $40 \%$ hold the rank of associate professor, $26 \%$ hold the rank of professor, and $4 \%$ hold the rank of eminent scholar. The average number of years in the profession for the combined group is 19.17 . Approximately $14 \%$ of the full sample of faculty has administrative duties, $29 \%$ are female, $25 \%$ are nonwhite, and the average number of "good" published, peer-reviewed research studies in the preceding five years is 3.49, where "good" journals include only those journals included on the Australian Business Deans Council (ABDC) 2010 list of approved journals. The ABDC list is increasingly being recognized as a validated list of credible, peer-reviewed research outlets for business faculty (see www.abdc.edu.au, accessed on 8/27/16). The table also shows the distribution of the faculty in the full sample across business disciplines: $20 \%$ in accounting, $13 \%$ in economics, $13 \%$ in finance, $16 \%$ in information systems/operations management, $25 \%$ in management, and $13 \%$ in marketing.

Table 1. Summary statistics for both business schools combined

$\mathrm{N}=142$ Faculty Members

\begin{tabular}{|c|c|c|c|}
\hline Variable & Mean & $\begin{array}{l}\text { Standard } \\
\text { Deviation }\end{array}$ & Definition \\
\hline
\end{tabular}




\begin{tabular}{|c|c|c|c|}
\hline$S A L A R Y$ & 113,392 & 30,586 & 2013-2014 Salary \\
\hline INSTRUCTOR & 0.08 & - & Instructor rank \\
\hline ASSISTANT & 0.21 & - & Assistant professor rank \\
\hline ASSOCIATE & 0.40 & - & Associate professor rank \\
\hline PROFESSOR & 0.26 & - & Professor rank \\
\hline EMINENTSCHOLAR & 0.04 & - & Eminent scholar rank \\
\hline YEARS & 19.17 & 10.75 & Years in profession \\
\hline ADMINDUTY & 0.14 & - & $\begin{array}{l}\text { Assignment includes administrative } \\
\text { duties }\end{array}$ \\
\hline FEMALE & 0.29 & - & Female gender \\
\hline NONWHITE & 0.25 & - & Nonwhite race \\
\hline$A B D C$ & 3.49 & 4.03 & $\begin{array}{l}\text { Number of "good" published research } \\
\text { studies }\end{array}$ \\
\hline ACCOUNTING & 0.20 & - & Accounting discipline \\
\hline ECONOMICS & 0.13 & - & Economics discipline \\
\hline FINANCE & 0.13 & - & Finance discipline \\
\hline ISOM & 0.16 & - & $\begin{array}{l}\text { Information systems and operations } \\
\text { management discipline }\end{array}$ \\
\hline MANAGEMENT & 0.25 & - & Management discipline \\
\hline MARKETING & 0.13 & - & Marketing discipline \\
\hline
\end{tabular}

Table 2 shows similar summary statistics for each business school in the sample. Notably, the average salary is less at the non-tenure granting school, but the ranks of faculty are more evenly dispersed at this school. Indeed, $47 \%$ of the faculty at the tenure granting school holds the rank of associate professor. The average number of years in the profession as denoted by YEARS is 19.58 at the non-tenure granting business school while for the tenure granting business school YEARS is 18.95. Research productivity is similar at the two schools, with faculty at the non-tenure granting school publishing 3.42 "good" articles, on average, in the preceding five years and the faculty at the tenure granting school publishing 3.52 "good" articles, on average, in the preceding five years. 


\section{Ml Macrothink}

International Journal of Accounting and Financial Reporting

ISSN 2162-3082 2019, Vol. 9, No. 1

\section{Earnings Equation}

Using a model similar to that used in other studies related to faculty earnings determinants [Toutkoushian et al., (2007), Mittal et al., (2008), Park (2011), and Allen et al., (2015)] the earnings equation is shown in equation 1.

$$
Y_{\mathrm{i}}=\mathrm{X}_{\mathrm{i}} \beta+\varepsilon_{i}
$$

From Equation $1, Y_{\mathrm{i}}$ is the salary of the $\mathrm{i}^{\text {th }}$ individual and $\mathrm{X}$ is a matrix of independent variables that are hypothesized to affect earnings with weights in vector $\beta$. The control variables in matrix $\mathrm{X}$ include binary variables that indicate gender, race, administrative duties, years in the profession, research productivity, faculty rank (instructor, assistant professor, associate professor, professor, and eminent scholar), and academic discipline (accounting, economics, finance, information systems/operations management, management, and marketing). The random error term is represented by $\varepsilon$.

Table 2. Summary statistics by business school

\begin{tabular}{lllll}
\hline & \multicolumn{2}{l}{ Non-Tenure Granting School } & \multicolumn{2}{l}{ Tenure Granting School } \\
\hline & $\mathrm{N}=50$ Faculty Members & N = 92 Faculty Members \\
\hline Variable & Mean & Standard Deviation & Mean & Standard Deviation \\
\hline SALARY & 109,414 & 34,148 & 115,554 & 28,429 \\
\hline INSTRUCTOR & 0.08 & - & 0.09 & - \\
\hline ASSISTANT & 0.28 & - & 0.17 & - \\
\hline ASSOCIATE & 0.28 & - & 0.47 & - \\
\hline PROFESSOR & 0.28 & - & 0.25 & - \\
\hline EMINENTSCHOLAR & 0.08 & - & 0.02 & - \\
\hline YEARS & 19.58 & 11.86 & 18.95 & 10.16 \\
\hline ADMINDUTY & 0.12 & - & 0.15 & - \\
\hline FEMALE & 0.32 & - & 0.27 & - \\
\hline NONWHITE & 0.16 & - & 0.29 & - \\
\hline
\end{tabular}




\begin{tabular}{lllll}
\hline ABDC & 3.42 & 3.31 & 3.53 & 4.39 \\
\hline ACCOUNTING & 0.20 & - & 0.21 & - \\
\hline ECONOMICS & 0.14 & - & 0.13 & - \\
\hline FINANCE & 0.10 & - & 0.14 & - \\
\hline ISOM & 0.22 & - & 0.13 & - \\
\hline MANAGEMENT & 0.22 & - & 0.26 & - \\
\hline MARKETING & 0.12 & - & 0.13 & - \\
\hline
\end{tabular}

Estimating the model parameters, $\beta$, using Ordinary Least Squares (OLS) regression analysis provides the results discussed in the next section. Using OLS assumes that the dependent variable $S A L A R Y$ is approximately linearly related to the independent variables in matrix $\mathrm{X}$, and that a) the residuals are statistically independent or uncorrelated with each other (i.e., $\left.\left.\operatorname{Cov}\left(\varepsilon_{\mathrm{i}}, \varepsilon_{\mathrm{j}}\right)=0 \forall \mathrm{i} \neq \mathrm{j}\right) ; \mathrm{b}\right)$ there is no collinearly between the independent variables; and c) the expected value of the residuals is zero $(\mathrm{E}(\varepsilon)=0)$, they have constant variance $\left(\operatorname{Var}(\varepsilon)=\sigma^{2}\right)$, and are normally distributed $\left(\varepsilon \sim \mathrm{N}\left(0, \sigma^{2}\right)\right)$.

\section{Estimation Results}

Table 3 shows estimates of the parameters by OLS for the earnings equations for the full sample and Table 4 shows the regression results by individual schools. Note that in all specifications of the regression, the omitted comparison categories for the binary variable groups "rank" and "discipline" is INSTRUCTOR and MANAGEMENT, respectively. Also note that additional control variables were considered for inclusion in the earnings equation (including career publication totals and years at the institution), but were ultimately excluded from the model due to their high levels of multicolinearity with other variables (variance inflation factors greater than 20).

The results in Table 3 show significant salary differences by faculty rank, with evidence of salary inversion for associate professors relative to assistant professors and for faculty with more years in the profession. Faculty with administrative assignments are significantly compensated for this additional activity and faculty with increased research productivity receive significantly more salary dollars. The results suggest no significant salary effects for gender or race.

Focusing on the variables of primary interest in this study, the results strongly support the notion that accounting and finance faculty are paid premium salaries relative to management, marketing, and information systems/operation management faculty and that economics faculty are paid significantly discounted salaries compare to faculty in all other business disciplines. The coefficient on the binary control variable indicating the tenure granting 
school is significant and suggests that faculty at this school are generally paid larger salaries than faculty at the non-tenure granting school.

Table 4 shows the results of estimating the earnings equation separately for each school in the sample. The overall fit of the model is better for the non-tenure granting business school with an $R^{2}$ of $89.99 \%$, but an $R^{2}$ of only $60.70 \%$ for the tenure granting business school. The models have $F$-statistics of 22.47 and 8.50 for the non-tenure granting and tenure-granting business schools, respectively, that are significant at the $1 \%$ level.

The results by school again show evidence of salary inversion for associate professors relative to assistant professors and, at the non-tenure granting school only, for faculty with more years in the profession. Faculty with administrative assignments at both schools is significantly compensated for those activities. The results indicate no salary effects related to race or gender. Increased research productivity is positively and significantly related to salary ( $p$-value of 0.09) at the tenure granting school, but is not related to salary at the non-tenure granting school.

Focusing on the variations in salary by business discipline at the two schools, the results indicate that accounting and finance faculty receive salary premiums at the non-tenure granting school and that only accounting faculty receives salary premiums at the tenure granting school. At both schools, economics faculty suffers significant salary discounts relative to all other business disciplines.

Notably, the discount for economics faculty is larger at the non-tenure granting school and the premium for finance faculty is larger at the non-tenure granting school. The premium for accounting faculty is larger at the tenure granting school. Overall, these findings indicate differential salary premiums and discounts across business disciplines in general and across schools with different employment contracting systems in particular.

\section{Conclusion}

This study considers determinants of salaries for business school faculty with an emphasis on the variations in salaries across business disciplines and employment contracting systems. Using sample data from two public universities in Florida that use different employment contracting systems (tenure and non-tenure granting schools), the analysis strongly suggests that accounting faculty receive significant salary premiums and that economics faculty receive significant salary discounts. The analysis also shows that finance faculty at the non-tenure granting business school also receive a salary premium. These findings are consistent with the notion that accounting and finance faculty have high opportunity costs for pursuing academic rather than professional careers.

Table 3. Regression results for both schools combined

$\mathrm{N}=142$ Faculty Members

Dependent Variable $=S A L A R Y$ 


\begin{tabular}{llll} 
Variable & Coefficient & Standard Error & $p$-value \\
\hline ASSISTANT & $36,139.82$ & $6,312.40$ & 0.00 \\
\hline ASSOCIATE & $34,603.90$ & $5,968.60$ & 0.00 \\
\hline PROFESSOR & $60,709.74$ & $6,713.97$ & 0.00 \\
\hline EMINENTSCHOLAR & $100,158.03$ & $9,991.25$ & 0.00 \\
\hline YEARS & -781.12 & 176.62 & 0.00 \\
\hline ADMINDUTY & $21,962.61$ & $4,669.64$ & 0.00 \\
\hline FEMALE & -859.95 & $3,461.88$ & 0.80 \\
\hline NONWHITE & 59.76 & $3,712.38$ & 0.99 \\
\hline ABDC & 794.79 & 444.87 & 0.08 \\
\hline ACCOUNTING & $17,228.98$ & $4,548.10$ & 0.00 \\
\hline ECONOMICS & $-18,327.06$ & $5,485.48$ & 0.00 \\
\hline FINANCE & $17,227.03$ & $5,733.85$ & 0.00 \\
\hline ISOM & $2,900.37$ & $4,986.17$ & 0.56 \\
\hline MARKETING & -431.59 & $5,380.27$ & 0.94 \\
\hline TENURE GRANTING SCHOOL & $9,070.67$ & $3,304.16$ & 0.01 \\
\hline constant & $71,611.26$ & $6,758.85$ & 0.00 \\
\hline$R^{2}$ & $70.10 \%$ & & \\
\hline -statistic & 19.70 & & \\
\hline & & & \\
\hline
\end{tabular}

As expected, faculty rank and administrative duties are also significant determinants of salary levels in both the tenure-granting and non-tenure granting business schools. The findings in this study do not support the contention of racial or gender discrimination in salary levels at either school, but do suggest that greater research productivity is related to higher salaries at the tenure granting school. The results provide evidence of salary inversion for associate professors relative to assistant professors at both schools.

Some other variables are only significant in one business school. For example, whereas research productivity is an important determinant in the tenure-granting business school (due possibly to the long-term nature of tenure, and with many professors seeking promotion to the next rank), years in the profession is a significant variable determining salary level in the non-tenure granting business school. This could be caused by more frequent job changes by 
faculty at the non-tenure granting business school: there is no tenure to tie them to the institution. Assuming that the motivating factor in job search is salary, then given the same number of years, faculty at non-tenure granting institutions will not only have higher salaries, but the changes in salary over the years could also be more significant. This tendency for faculty at the non-tenure granting business school to change jobs more often is indicated in Table 2 that shows the average years at the institution for professors to be greater in the tenure-granting business school than in the non-tenure granting business school. It should also be noted that when the number of years in the profession is considered along with the premium for assistant professors, it decreases the salary inversion premium of assistant professors over associate professors at the non-tenure granting business school.

Table 4. Regression results for both schools combined

Dependent Variable $=$ SALARY

Non-Tenure Granting School

Tenure Granting School

\begin{tabular}{|c|c|c|c|c|c|c|}
\hline Variable & Coefficient & $\begin{array}{l}\text { Standard } \\
\text { Error }\end{array}$ & $p$-value & Coefficient & $\begin{array}{l}\text { Standard } \\
\text { Error }\end{array}$ & $p$-value \\
\hline ASSISTANT & $40,910.55$ & $7,905.50$ & 0.00 & $36,490.71$ & $9,068.05$ & 0.00 \\
\hline ASSOCIATE & $38,405.04$ & $7,653.48$ & 0.00 & $28,839.57$ & $8,488.15$ & 0.00 \\
\hline PROFESSOR & $71,846.80$ & $8,367.71$ & 0.00 & $48,817.58$ & $10,519.01$ & 0.00 \\
\hline EMINENTSCHOLAR & $119,213.00$ & $11,147.99$ & 0.00 & $72,376.90$ & $17,855.57$ & 0.00 \\
\hline YEARS & $-1,105.29$ & 193.55 & 0.00 & -321.84 & 306.81 & 0.30 \\
\hline ADMINDUTY & $21,351.59$ & $6,447.21$ & 0.00 & $23,883.92$ & $6,167.16$ & 0.00 \\
\hline FEMALE & $2,228.71$ & $4,429.90$ & 0.62 & $-3,202.73$ & $4,802.56$ & 0.51 \\
\hline NONWHITE & 564.77 & $6,144.09$ & 0.93 & $3,915.55$ & $4,928.32$ & 0.43 \\
\hline$A B D C$ & -253.79 & 887.50 & 0.78 & 946.80 & 542.34 & 0.09 \\
\hline ACCOUNTING & $11,791.63$ & $6,256.15$ & 0.07 & $19,643.02$ & $6,231.64$ & 0.00 \\
\hline ECONOMICS & $-20,465.45$ & $6,649.98$ & 0.00 & $-18,819.90$ & $7,668.25$ & 0.02 \\
\hline FINANCE & $35,401.89$ & $9,278.03$ & 0.00 & $10,149.52$ & $7,390.26$ & 0.17 \\
\hline
\end{tabular}




\begin{tabular}{lllllll}
\hline ISOM & $-1,870.25$ & $6,091.29$ & 0.76 & $3,611.12$ & $7,183.16$ & 0.62 \\
\hline MARKETING & $10,517.96$ & $7,146.91$ & 0.15 & $-7,321.08$ & $7,347.77$ & 0.32 \\
\hline Constant & $72,810.83$ & $8,819.40$ & 0.00 & $78,238.08$ & $8,422.92$ & 0.00 \\
\hline$R^{2}$ & $89.99 \%$ & & $60.70 \%$ & \\
\hline F-statistic & 22.47 & & & & \\
\hline
\end{tabular}

For many graduate programs in which enrollment for accounting and finance disciplines exceed those for other disciplines, these results could suggest that students armed with the knowledge of salary premiums and discounts are self-selecting more into accounting and finance programs than other graduate business programs. This could be a signal for business school deans, chairs, and directors to look more carefully at the allocation of resources. The results also indicate that the granting of tenure has value, in that faculty turnover is relatively lower at tenure-granting institutions.

As with all empirical studies such as this one, the generalizability of these results is limited by potentially omitted variables in the analysis and sample bias. For example, no variables are included to control for variation in teaching or service effectiveness. Additionally, the small sample size of 192 observations from only two business schools limits the ability to extend these results to all business schools. Even so, the results provide insights that could prove valuable to administrators and faculty members who seek to better understand salary levels across business disciplines, especially when contemplating salary adjustments, new job opportunities, and employment contracting systems.

\section{References}

Allen, M., Jones, T., \& Rhodd, R. (2015). Faculty Salary Compression: Years at the Institution or Years in the Profession?. Financial Decisions, 27(2).

Ashraf, J., \& Shabbir, T. (2006). Are There Racial Differences in Faculty Salaries?. Journal of Economics and Finance, 30(3).

Bergeth, C. (2007). Wage Differentiation Among University Professors: Evidence from UNI's College of Business Administration. Major Themes in Economics, Spring, 25-39.

Boudreau, N., Sullivan, J., Balzer, W., Ryan, A. M., Yonker, R., Thorsteinson, T., \& Hutchinson, P. (1997). Should Faculty Rank Be Included as a Predictor Variable in Studies of Gender Equity in University Faculty Salaries?. Research in Higher Education, 38(3).

Ehrenberg, R., Hirschel, K., \& Rees, D. (1990). Faculty Turnover at American Colleges and Universities: Analysis of AAUP Data. NBER Working Paper \#3239. 


\section{Ml Macrothink}

International Journal of Accounting and Financial Reporting

ISSN 2162-3082 2019, Vol. 9, No. 1

Finch, J. H., Allen, R. S., \& Weeks, H. S. (2010). The Salary Premium Required for Replacing Management Faculty: Evidence from a National Survey. Journal of Education for Business, 85, 264-267.

Kreuter, N. (2012). Essay on What Faculty Members Need to Know About Salaries, Inside Higher Education. Retrieved March 25, 2019, from https://www.insidehighered.com/advice/2012/09/05/essay-what-new-faculty-members-needknow-about-salaries

Lavania, D., Sharma, H., \& Gupta, N. (2011). Faculty Recruitment and Retention: A Key for Managing Talent in Higher Education. International Journal of Enterprise Computing and Business Systems, 1(2).

Martinello, F. (2009, October). Faculty Salaries in Ontario: Compression, Inversion, and the Effects of Alternative Forms of Representation. ILR Review, 63(1), 128-145.

Mohanty, D. Q., Dodder, R. D., \& Aù Karman, T. (1986). Faculty Salary Analyses by Region, Rank, and Discipline from 1977-1978 to 1983-1984. Research in Higher Education, 24(3).

Sinha, C., \& Sinha, R. (2012). Factors Affecting Employee Retention: A Comparative Analysis of two Organizations from Heavy Engineering Industry. European Journal of Business and Management, 4(3).

Yang, L. J., \& Webber, K. L. (2015). A Decade Beyond the Doctorate: The Influence of a US Postdoctoral Appointment on Faculty Career, Productivity, and Salary. Research in Higher Education, 70(4), 667-687.

\section{Copyright Disclaimer}

Copyright for this article is retained by the author(s), with first publication rights granted to the journal.

This is an open-access article distributed under the terms and conditions of the Creative Commons Attribution license (http://creativecommons.org/licenses/by/4.0/) 